\title{
INVESTIGATING THE IMPACT OF LEARN BY DOING IN CIVIL TECHNOLOGY CLASS: STUDENTS ACTION
}

\author{
Khojane Geoffrey Mokhothu \\ Department of Mathematics, Science and Technology Education, Central University of Technology \\ Free State (South Africa)
}

\begin{abstract}
Learn by doing is one of the critical teaching approaches in Civil Technology as a subject, of which it consists of both theoretical work and practical skills. The study aims to explore the effectiveness of hand-on skills learning as a teaching approach in Civil Technology class. While the main objective of the study is to examine the impact of hands-on skills learning in Civil Technology. The study used a mixed-method approached to collect data which of consist quantitative (practical test) and qualitative (presentations). Purposive sampling was used to select 20 participants, from different gender (males and females) also from a diverse background. Findings of the study reveal that students managed to demonstrate competence in totality (both theory and practical) and also by completing their work within the scheduled time.
\end{abstract}

Keywords: Learn by doing, hands-on, civil technology.

\section{Introduction}

Learn by doing regarded as significant teaching and learning approach which is exploring students in reality through critical thinking and problem solving. It also promotes the integration of theory and practical of which is key aim of the subject civil technology to prepare student in-totality which means students should be found competent in both theoretical content knowledge and practical work. Maeko and Makgato (2014) proclaim that subject Civil Technology is developed to equip students with a sound technical foundation skill that merge theory and practical. Hence, Mokhothu (2019) attest that Civil Technology's main aim and objective are to prepare and assess students as critical problem solves. Therefore, above mentioned aim and objective can be achieved and validated through or when students are hand-on.

\section{The conceptualisation of the study}

\subsection{Learn by doing}

Learn by doing is an explanation of a concept action learning. which is has been describe by many authors such as Revans (1980); Mumford (1996; 2006) and McNiff (2013) when pronounce that action learning is "learning by doing" and its strength is grounded by group work (sets). Which should serve as producers of "development, intellectual, emotional or physical that require its subject", through responsible meeting in some actual problem that will expand their learning skills (Revans, 1982; McNiff, 2013). Therefore, Pedler (1991), argues learning by doing from perspective of the quotes "there is no learning without action and no sober and deliberate action without learning" which kick start the statement saying learning by doing is an approach to the development of both students and lectures, which grasp activity as reinforcement for learning.

\subsection{Civil technology}

Civil Technology is a subject which is offered at high school level in South Africa from grade 10 to 12 and is divided into three categories: Construction, Civil Services and Woodwork. Its main focus is to introduce learners to the concepts and principles in the built environment and technological process. Moreover, it promotes theory that involves scientific and mathematical principles and practical skills (DoE, 2014; Mokhothu, 2015-2019). According to Maeko and Makgato (2014:324) the subject Civil Technology is designed to provide learners with a sound technical foundation that integrates both theory and practical competencies. 


\subsection{Hand-on}

According to Kennedy (2011) Hands-on skills are found in many fields of technology education, such as electrical technology, mechanical technology and civil technology (Kennedy, 2011:54). In Civil Technology, hands-on expertise in healthy working practices will be built through the combined completion of the theoretical work and the practical assessment tasks (PAT); good housekeeping; first aid procedures; structural erection; working with precise measurements; and laboratory practice. (Department of Basic Education, DBE, 2011:9; Maeko and Makgato, 2017:227).

\section{The aim of the study}

The study aimed to investigating the impact of "learn by doing" in Civil Technology class through student's action theory and practical work to promote hands-on.

\section{The objective}

The main objective of the study is to measure the impact of "learn by doing" in Civil Technology class through student's action/ hands-on.

\section{Proposition}

"Learn-by-doing" has a significant impact on critical thinking, creativity, innovation and critical problem-solving skills in the integration of theory (content knowledge) and practical work in civil technology.

\section{Methodology}

\subsection{The context of the study}

A formal Civil Technology class was attended by student enrolled Bachelor of Education Senior Phase and Further Education and Training Phase: Technology (B.Ed. SP\&FET). Setting-out of foundation, topic was presented by lecturer. The study was conducted during the third term of their first academic year of studies. At the end of presentation, the assessment task was assigned to students which consist of: Practical test and Video presentation.

\subsection{Participants}

Participants were all Civil Technology first year students enrolled at one of University of Technologies in South Africa. The total number of participants was 64 consist of 38 (59.4\%) males and $26(40.6 \%)$ female all from different cultural groups. All participant's respondent positively (100\%).

\subsection{Measures}

In the first stage, students were instructed to divide into 8 groups consisting of 8 members of the group and also to record a video of the entire process from the initial stage to the end. The lecturer carried out an assessment activity which states as follows: students should identify their own construction site, perform site clearance using the correct tools, use the correct tools to set up a foundation using the 3-4-5 method, and develop an observation tool to report on a video recorded. Submit your video by e-mail before the date of play (presentation).

\section{Results presentation, interpretation and discussion}

\subsection{Practical test}

Table below present the results of practical test form site clearance to setting-out. The results presented in frequency, marks and percentage (\%)

Table 1. Practical test results.

\begin{tabular}{|l|c|c|c|c|}
\hline Groups & Frequency & Marks (50) & \% & Average \\
\hline Group A and C & 2 & 41 & 82 & \multirow{2}{*}{$\mathbf{7 5 . 5}$} \\
\cline { 1 - 4 } Group B and F & 2 & 40 & 80 & \\
\cline { 1 - 4 } Group D & 1 & 38 & 76 & \\
\cline { 1 - 4 } Group E, G and H & 3 & 34 & 68 & \\
\hline
\end{tabular}


The results above indicate that group A and group B has obtained the highest score percentage $(82 \%)$, followed by group B and F with the score of $(80 \%)$. While group D managed the score of $(76 \%)$, then group E, G and $\mathrm{H}$ has scored the lowest at (68\%). However, the average score is high with $75.5 \%$. therefore, that means students managed to enjoy practical work (hands-on) as deemed it has allowed the students to apply their own critical thinking and creativity to solve their own problem. Which the above results concur with Revans (1980); Mumford (1996; 2006) and McNiff (2013) when they pronounce that action learning is "learning by doing" and its strength is grounded by group work (sets). Which should serve as producers of "development, intellectual, emotional or physical that require its subject", through responsible meeting in some actual problem that will expand their learning skills (Revans, 1982; McNiff, 2013).

\subsection{Presentation}

Table below present the results of presentation of the video and observation to reflect on the performance. The results presented in marks and percentage $(\%)$

Table 2. Presentation results.

\begin{tabular}{|c|c|c|c|}
\hline Groups & Marks (50) & $\%$ & Average \\
\hline Group A & 40 & 80 & \multirow{8}{*}{71.8} \\
\hline Group B & 40 & 80 & \\
\hline Group C & 40 & 80 & \\
\hline Group D & 36 & 72 & \\
\hline Group E & 36 & 72 & \\
\hline Group F & 35 & 70 & \\
\hline Group G & 30 & 60 & \\
\hline Group $\mathrm{H}$ & 30 & 60 & \\
\hline
\end{tabular}

Table 2 above presents that group A, B and C has managed to score high with the percentage of $(80 \%)$, followed by group $\mathrm{D}$ and $\mathrm{E}$ with the percentage of $(72 \%)$. When group $\mathrm{F}$ managed the score of (70\%). Then group $\mathrm{G}$ and $\mathrm{H}$ came last with percentage score of $(60 \%)$. But the average percentage score still maintained high score of $71,8 \%$ which confirming that students managed to lean on their own while doing and trying and eventually found competent while their reflecting their practices from the observation tool and video. Data collected above concur with Maeko and Makgato (2017:227) when they affirm that in Civil Technology, hands-on expertise in healthy working practices will be built through the combined completion of the theoretical work and the practical assessment tasks (PAT); good housekeeping; first aid procedures; structural erection; working with precise measurements; and laboratory practice. Therefore, Pedler (1991) was accurate when stating that learning by doing from perspective of the quotes "there is no learning without action and no sober and deliberate action without learning".

\section{Conclusion}

In conclusion, this study has proven that learn-by-doing is one of the significant teaching and learning methods in Civil Technology. As it allows the student to hand-on and uses tools and experience on their own. Students managed to survive and grasp a clear individualised interpretation of theory and transfer it to actual practical work. Therefore, the study has also proved that Civil Technology student should not be overloaded with theory only but be allowed to integrate theoretical content with practical work to advance their technical skills.

\section{References}

Kennedy OO 2011. Reappraising the Work Skill Requirements for Building Technology Education in Senior Secondary School for Optimum Performance in Nigeria. European Journal of Applied Sciences. 3 (2): 46-52. IDOSI Publications

Maeko MSA, Makgato M 2014. Skills training through hands-on practical activities in civil technologya case study of three technical schools in South Africa. The Journal for Transdisciplinary Research in Southern Africa, 10(3): 293-309. 
Maeko MSA, Makgato M 2017. The Transfer of Requisite Civil Technology Hands-on Practical Skills to Student Teachers in South African Civil Technology Teacher Training Universities. International Journal of Educational Sciences, 18(1-3), 147-157

Mokhothu KG 2015. The Integration of Technical Subjects in Civil Technology Curriculum with Special Reference to FET Technical Schools. MEd Dissertation. Bloemfontein: Central University of Technology Free State.

Mokhothu KG 2019. Preventing spectators in a group-work: Civil Technology student's perspective, C. Mafalda (Ed). Proceedings of 7th International Conference on Education and New Developments (END), 22-24 June, 2019. Porto, Portugal. Pp 117-120. ISBN: 978-989-54312-5-0

Morrison M 2017. Action Learning and Action Learning Sets- Reg Revans. https://rapidbi.com/actionlearning-sets/ [accessed: 15/01/2020]

Mumford A 2006. Action learning: nothing so practical as a good theory. Action Learning Research and Practice, 3(01): 69-76 